\title{
Nonspesifik semptomlu olgularda bruselloz sıklığı
}

\section{The frequency of brucellosis in nonspecific symptomatic cases \\ Dilara Yıldırım*, Haldun Sümer}

Mikrobiyoloji Laboratuvarı (Dr. D. Yıldırım), Sivas Numune Hastanesi, TR-58040 Sivas, Halk Sağlığı Anabilim Dalı (Prof. Dr. H. Sümer), Cumhuriyet Üniversitesi Tıp Fakültesi, TR-58140 Sivas

\section{Özet}

Amaç. Brucella spp. türü bakterilerin neden olduğu Bruselloz, tüm dünyada olduğu gibi ülkemizde de endemik olarak bulunmaktadır. Bu çalışmada 2011 Haziran, 2012 Ocak ayları arasında ateş, eklem ağrısı, halsizlik ve yorgunluk şikayeti ile çeşitli servislerden laboratuvarımıza başvuran 1429 hastada, brucellacapt testi sonuçları ve sedimentasyon sonuçlarının retrospektif olarak incelenmesi amaçlanmıştır. Yöntem. Testte Coombs test antijeni (Metser, İSTANBUL) kullanılarak brucellacapt yöntemi uygulandı. Sedimentasyon (Vacoplus, ESR120) değerlerine autoanalyzer cihazında fotometrik tüp yöntemi ile bakıldı. Bulgular. Çalışmamızda toplamda 103 hastada \%7,2 lik bir pozitiflik oranı görüldü. Pozitif hastaların \%6,2'si (n=49) kadın, \%8,5'i $(n=54)$ erkekti. Brusella pozitif ve brusella negatif hastalar arasında sedimentasyon değeri açısından doğrudan bir ilişki bulunmadı $(\mathrm{p} \geq 0,195)$. Sonuç. Morbiditesi yüksek bir hastalık olan bruselloz, bölgemizde sık denilecek bir oranda görülmektedir. Nonspesifik semptomları olan hastalarda, akılda tutulması ve araştırılması gerekmektedir.

Anahtar sözcükler: Brucella spp., brucelloz, brucellacapt testi, sedimentasyon

\begin{abstract}
Aim. Brucellosis, caused by Brucella spp. type bacterium is an endemic disease in our country like all over the world. In this study, we aimed analysing retrospectively the results of brucellacapt test and sedimantation in 1429 patient applicated to our laboratory with high temperature, joint pain, weakness and fatigue complaints between 2011 June and 2012 January from different services. Method. In the test, brucellacapt method was performed using Coombs test antigen. Sedimantations were evaluated with photometric tube method in autoanalyzer device. As a total, $7.2 \%$ positivity was detected in 103 patient $6.2 \%$ of patients detected positive were women $(n=49)$ and, $8.5 \%$ of them are male $(n=54)$. Result. There is no correlation for sedimantation between brucella positive and brucella negative patients $(\mathrm{p} \geq 0,195)$. Conlusion. Brucellosis disease that has high morbidity occurs in our region frequently. It must be thought and researched in the patients who have nonspecific symptoms.
\end{abstract}

Keywords: Brucella spp., brucellosis, brucellacapt test, sedimentation

Geliş tarihi/Received: 20 Haziran 2013; Kabul tarihi/Accepted: 03 Ekim 2013

\section{*İletişim adresi:}

Dr. Dilara Yıldırım, Mikrobiyoloji Laboratuvarı, Sivas Numune Hastanesi, TR-58040 Sivas. E-posta: nidimay@gmail.com

Bu çalışma 19-13 Kasım 2013'de Antalya'da gerçekleştirilen 2.Ulusal Klinik Mikrobiyoloji Kongresinde poster olarak sunulmuştur.

\section{Giriş}

Bruselloz, Brucella türü bakterilerin neden olduğu, tüm dünyada yaygın görülen bir zoonozdur. Bruselloz çiftlik hayvanlarından insanlara bulaşır, çoklu sistem tutulumu ile seyreder. Brucella spp. vücutta birçok sistemi tutabilmektedir, enfeksiyon sırasında özellikle lenf nodlarına yerleşir, bakteriyemi oluşturur [1]. 
İnsan brusellozunun tanısında birçok test kullanılmıştır. Bruselloz için serum aglütinasyon testi (SAT) 1897 y1lında Wright tarafından geliştirilmiştir ve hala bir referans özelliği taşımaktadır. Bundan sonra geliştirilen diğer önemli testler Rose Bengal testi, kompleman fiksasyon testi, indirekt Coombs testi, hizlı dipstick testi, enzime bağlı immunosorban test (ELISA) ve son dönemde gündeme gelen, immunocaptureaglütinasyon testi olan brucellacapt (BCAP) testidir [2].

Brucellacapt testi, insan brusellozunun tanısında Coombs testine alternatif olarak önerilen bir immunocapture aglütinasyon testidir. Başlıca yüksek afinite antikorların belirlenmesi temeline dayanan BCAP testi, Coombs testinden daha spesifiktir. Bununla birlikte BCAP testinin Coombs testine alternatif olarak kullanımı söz konusu olduğunda, bazı relaps olgular, hastalığın kronik formları ve düşük afinite antikorlardaki küçük değişiklikler dikkat edilip ayrılmalıdır. Çünkü bu olgular Coombs testiyle daha iyi tespit edilmektedir [3].

Son yıllarda ELISA brusellanın serolojik tanısına dahil edilen bir yöntemdir. Temel avantajları hızlı ve otomatize olmasıdır. B. melitensis için spesifik ve sensitif double antikor sandviç ELISA yöntemi geliştirilmiştir. Geliştirilmiş ELISA yöntemi iyi bir üretkenlik sağlamakta ve yüksek özgüllük göstermektedir [4, 5].

$\mathrm{Bu}$ çalışmada, mikrobiyoloji laboratuvarımıza başvuran hastaların brucellacapt test sonuçları ile bruselloz sıklığının belirlenmesi ve sedimentasyon değerlerinin araştırılması amaçlanmıştır.

\section{Gereç ve yöntem}

Sivas Numune Hastanesi Mikrobiyoloji Laboratuvarına 2011 Haziran, 2012 Ocak ayları arasında ateş, eklem ağrısı, halsizlik ve yorgunluk şikayetleri ile çeşitli servislerden başvuran 1429 hastada, BCAP testi sonuçları ve sedimentasyon sonuçları retrospektif olarak incelendi.

$\mathrm{Bu}$ testte kullanılan Brucella Coombs test antijeni (Metser, ISTANBUL) smooth lipopolisakkarit (LPS) yapıdadır. B. abortus S99 Smooth-LPS, B melitensis biyotip3 ve B.suis' in insanlarda meydana getirdiği akut ve kronik brusellosisin teşhisinde kullanılır. Brusellosisde oluşan aglutinin IgG, IgM, IgA ve nonaglutinin IgG ve IgA'yı ortaya çıkarmaktadır.

Çalışmada insan kaynaklı IgG, IgM, IgA antikorlarına karşı antikorlarla kaplanmış kuyucuklarda, her örneğin yanı sıra, pozitif kontrol ve negatif kontrol çalışıldı. Her bir kuyucuğa $50 \mu \mathrm{l}$ CBT(Metser, İSTANBUL) dilüent koyuldu. Ayrı bir yerde bir tüp içerisinde $195 \mu \mathrm{l}$ CBT dilüenti üzerine $5 \mu \mathrm{l}$ hasta serumu ilave edilerek 1/40 titre elde edildi. Hazırlanan bu karışım ilk kuyucuğa pipetlendi, böylece 1/80 lik titre elde edilmiş oldu. Birinci kuyucuktan ikinciye $50 \mu \mathrm{l}$ aktarıld1, 1/160 titre ye ulaş1ld1, 2.kuyucuktan $50 \mu 1$ dişarı atıldı. Tüm kuyucuklara $50 \mu 1$ Brucella Coommbs test antijeni (Metser, İSTANBUL) dağıtıldı. 1. kuyucuk 1/160, 2. kuyucuk1/320 titrede oldu. Kuyucuklar özel kilit kapaklı inkübasyon kutusuna koyuldu. $18-24$ saat $37^{\circ} \mathrm{C}$ 'de inkübe edildi. İnkübasyon sonrasında iki kuyucukta da reaksiyon varsa 6 kuyucuk ile üst titre çalışmasına alındı. Mavi nokta şekli negatif, 1/160'ın üstü homojen bulanıklık pozitif olarak değerlendirildi. Sedimentasyon (Vacoplus, ESR120) auto analyzer cihazında fotometrik tüp yöntemi ile çalışıldı.

Verilerin analizi SPSS 15.0 for Windows programında yapıldı. Kategorik karşılaştırmalar iki ortalama arasındaki farkın önemlilik testi esas alınarak yapılmıştır.

\section{Bulgular}

Çalışmamızda 1429 hasta sonucu retrospektif olarak incelendi. Kadın hastalardaki yaş

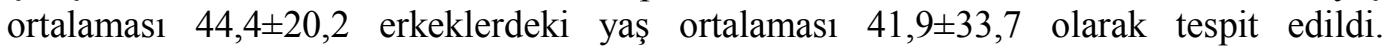
Hastaların 792(\%55,4)'si kadın, $637(44,6)$ 'si erkekti. Toplamda 103 hastada \%7,2 lik bir pozitiflik oranı görüldü. Pozitif hastaların \%6,2'si (n=49) kadın, \%8,5'i (n=54) erkekti. 
Hastaların \%61,2'si (n=63) intaniye servisinden, \%19,4'ü $(n=20)$ FTR servisinden $\% 3,9$ 'u $(\mathrm{n}=4)$ pediatri servisinden, \%15,5'i $(\mathrm{n}=16)$ diğer servislerden gelen hastalardı. 23 hasta 1/160, 44 hasta 1/320, 16 hasta 1/640, 4 hastada 1/1280, 10 hastada 1/2560, 6 hastada 1/5120 oranında pozitiflik tespit edildi. Sedimentasyon değerleri brusella pozitif $(n=103)$ hastalarda ortalama $22,40 \pm 18,50$ brusella negatif hastalarda $25,72 \pm 23,42$ değerinde bulundu. Brusella pozitif ve brusella negatif hastalar arasında sedimentasyon değeri açısından doğrudan bir ilişki bulunamadı $(\mathrm{p} \geq 0,195)$.

\section{Tartışma}

Brusellozun hızlı belirlenmesi ve tanımlanmasını sağlayan yeni tanısal tekniklerin geliştirilmesi ve laboratuar enfeksiyonu riskinin en az düzeye indirilmesi pratikte büyük öneme sahiptir. Brucellacapt testi, yeni diagnostik yöntemler arasında sık kullanılmaya başlayan seçeneklerden birisidir. Yapılan çalışmalar brucellacapt kitinde kullanılan teknolojinin, hem akut, hem de kronik hastalıkların belirlenmesinde çok yararlı olduğunu ve endemik alanlarda kolay, kullanılabilir bir yöntem olabileceğini ileri sürmektedir. Brucellacapt testinin diğer avantajları ise hızlı performans, basit kullanım ve işlemler, bütün reagentleri kapsayan kolay paketleme, yıkama ihtiyacının olmaması ve 24 saatte kolay okumadir. Brucellacapt ve (IgG+IgM) ELISA testleri brusellozun tanisinda sik başvurulan yöntemlerdir [6].

Orduna ve ark. [7] brucellacapt ve Coombs testlerinin duyarlılığını, eşik titresi 1/160 olarak alındığında sırasıyla $\% 95,1$ ve $\% 91,4$, özgüllüğünü ise $\% 81,5$ ve $\% 96,2$ olarak bildirmiş; eşik titresi 1/320 olarak alındığında duyarlılığın sırasıyla \%91,5 ve \%82,9, özgüllügün ise \%97,4 ve \%100 olduğunu ifade etmişlerdir.

Ardıç ve ark. [8] Coombs testini referans test, eşik titresini ise 1/160 olarak kabul ettiklerinde, duyarlılık, özgüllük, pozitif ve negatif prediktif değerlerinin, brucellacapt testi için sırasıyla, \%97,3, \%55,6, \%90 ve \%83,3 olarak bulmuşlardır. Bu araştırıcılar eşik titresini $1 / 320$ olarak aldıklarında bu değerlerin sirasıyla, \%100, \%59,1, \%88,6 ve $\% 100$ olduğunu vurgulamışlardır. Tanı anında brucellacaptin duyarlılığı (\%96) Coombs testi $(\% 100)$ ile benzer, SAT'tan (\%73) ise bir miktar yüksektir. Brucellacapt'in özgüllügü ise $(\% 97,5)$ SAT ve Coombs testinden $(\% 100)$ düşüktür. Brucellacapt ve Coombs testinin insan brusellozunun tanısında benzer duyarlılık ve özgüllük gösterdiğini söylemek mümkündür. Buna ek olarak brucellacapt, Coombs testinde olduğu gibi, SAT ile tespit edilemeyen değişim geçirmiş uzun süreli olgularda tanıya yardımcı olabilmektedir [9].

Ülkemizde bruselloz sıklığı 1990 yılından sonra artış göstermiştir. Bunun sebebi geri bildirimin daha düzenli yapılmaya başlanması ile açıklanabilir. Yapılan çalışmalarda hastalık en s1k \% 49,2'lik bir oranda Güneydoğu Anadolu Bölgesi'nde görülmüsstür. Doğu Anadolu Bölgesi'nde \%21,7, İç Anadolu Bölgesi'nde \%19,9, Ege Bölgesi'nde \%5 oranında görülürken, Karadeniz Bölgesi’nde \%0,1 oranında görülmüştür [10].

Alim ve ark. [11] 2006 yılında Sivas’ta yaptıkları çalışmada seropozitiflik oranını \%15,1 olarak belirlemiş, Van'da kırsal alanda yapılan çalışmada \%26,7'ye kadar çıkan bir pozitiflik görülmüştür [12].

Kayseri ve Afyon'un köylerinde yapılan çalışmada \%3,4 ve \%4,8 olarak tespit edilen seropozitiflik oranları, Karabay ve ark. [15] tarafından tarım ve hayvancılığın daha az yapıldığ Bolu' da yapılan çalışmada \%1 olarak tespit edilmiştir [13].

Demiroğlu ve ark. [16] Felek ve ark. [17] yaptıkları çalışmalarda brusellada yaş aralığını sırasıyla 15-79 ve 17-73 yıl olarak saptamışlardır ve olguların yaklaşık \%59'unun kadın olduğunu belirtmişlerdir. Cinsiyetler arasında önemli bir fark bulamamışlardır. Brusellozun düşük insidansa sahip olduğu ülkelerde, mesleki risk nedeniyle hastalığın erkeklerde daha yaygın olmasına karşın endemik olduğu ülkelerde cinsiyet farkı olmadığı bildirilmektedir. 
Ülkemizde de bildirilen olgu serilerinde cinsiyet açısından büyük farklara rastlanmamaktadır. Ancak Koşar ve ark. [18] yaptıkları çalışmada brusellanın \%64'lük bir oran ile kadınlarda daha fazla görüldüğünü, bunun da kırsal kesimde, hayvan bakımı, süt ve süt ürünlerinin hazırlanması gibi işlerde, kadınların daha çok çalışmasına bağlanabileceğini belirtilmişlerdir.

Bizim çalışmamızda da, kadın ve erkeklerde hastalığın sıklığı arasında anlamlı bir fark bulunmamıştır. Çalışmamızda tespit ettiğimiz semptomatik hastalardaki \%7,2'lik seropozitiflik oranı bölgemizin tarım ve hayvancılıkla geçinen bir bölge olması sebebiyle diğer bölgelerle uyumludur. Ateş, eklem ağrısı, halsizlik ve yorgunluk şikayeti ile başvuran olgularda, brusella akla gelmeli ve ülkemizde halen bir sağlık sorunu olmaya devam ettiği düşünülerek, araştırılması gerekmektedir.

\section{Kaynaklar}

1. WinnW, Allen S, JandaW, Koneman E. Koneman. Color Atlas and Textbook of Diagnostic Microbioloji. Sixth edition. Lipipincott Willams and Wilkıns 2006; 482-3.

2. Gomez MC, Nieto JA, Rosa C, Geijo P, Escribano MA, Munoz A, Lopez C. Evaluation of Seven Tests for Diagnosis of Human Brucellosis in an Area Where the Disease Is Endemic. Clin Vaccine Immunol 2008; 15: 1031-3.

3. Casanova A, Ariza J, Rubio M, Masuet C, Diaz R. Brucellacapt versus Classical Tests in the Serological Diagnosis and Management of Human Brucellosis. Clin Vaccine Immunol 2009; 16: 844-51.

4. Mantecon MA, Gutierrez P, del Pilar Zarzosa M, Duenas AI, Solera J, FernandezLago L, Vizcaino N, Almaraz A, Bratos MA, Rodriguez Torres A, OrdunaDomingo A. Utility of an immunocapture-agglutination test and an enzymelinked immunosorbent assay test against cytosolic proteins from Brucella melitensis B115 in the diagnosis and follow-up of human acute brucellosis. Diagn Microbiol Infect Dis 2006; 55: 27-35.

5. Jun M J, Xing Long W, Xiao LI. Development and verification of double antibody sandwich ELISA for B. melitensis. Chinese Journal of Biologicals 2009; 22: 823-5.

6. Peeridogaheh $\mathrm{H}$, Golmohammadi MG, Pourfarzi F. Evaluation of ELISA and Brucellacapt tests for diagnosis of Human Brucellosis. Iran J Microbiol 2013; 5: 14-8.

7. Orduna A, Almaraz A, Prado A, Gutierrez MP, Garcia-Pascual A, Duenas A, Cuervo M, Abad R, Hernandez B, Lorenzo B, Bratos MA, Torres AR. Evaluation of an immunocapture-agglutination test (Brucellacapt) for serodiagnosis of human brucellosis. J Clin Microbiol 2000; 38: 4000-5.

8. Ardic N, Ozyurt M, Sezer O, Erdemoğlu A, Haznedaroğlu T. Comparison of Coombs' and immunocapture-agglutination tests in the diagnosis of brucellosis. Chin Med J 2005; 118: 252-4.

9. Casao MA, Navarro E, Solera J. Evaluation of Brucellacapt for the Diagnosis of Human Brucellosis. J Infect 2004; 49: 102-8.

10. Ayaz C. Brusellozun Türkiye'deki Durumu KLİMiK X11. Türk Klinik Mikrobiyoloji ve İnfeksiyon Hastalıkları Kongresi 2005.

11. Alim A, Özdemir L, Arslan S, Nur N, Sümer H. Sivas'ın Bir Köyünde Brusella Seroprevalans1. Toplum Hekimliği Bülteni 2006; 25: 19-23.

12. Ceylan E, Irmak H, Buzğan T, Karahocagil MK, Evirgen Ö, Sakarya N, Akdeniz H, Demiröz AP. Van İline Bağlı Bazı Köylerde İnsan ve Hayvan Popülasyonunda Bruselloz Seroprevalansi. Van Tip Dergisi 2003; 10: 1-5.

13. Çetinkaya F, Naçar M, Aydın T, Koç N, Gökahmetoğlu S. Prevalence of brucellosis in the rural area of Kayseri, Central Anatolia, Turkey. Int J Infect Dis $2006 ; 10 ; 179-81$. 
14. Çetinkaya Z, Aktepe OC, Çiftci IH, Demirel R.Seroprevalence of human brucellosis in a rural area of Western Anatolia, Turkey. J Health Popul Nutr 2005; 23: 137-41.

15. Karabay O, Serin E, Tamer A, Gökdoğan F, Alpteker H, Ozcan A, Gündüz H. Hepatitis B carriage and Brucella seroprevalence in urban and rural areas of Bolu province of Turkey: a prospective epidemiologic study. Turk J Gastroenterol 2004; 15: 11-3.

16. Demiroğlu YZ, Turunç T, Alışkan H, Çolakoğlu S, Arslan H. Brucellosis: retrospective evaluation of the clinical, laboratory and epidemiological features of 151 cases. Mikrobiyol Bul 2007; 41; 517-27.

17. Felek S, Açık Y, Özden M. Çĭg köfte yeme alışkanlığı ile Brucella infeksiyonu seroprevalansı arasındaki ilişkinin araştırılması. Klimik Derg 1999; 12; 104-6.

18. Koşar A, Aygündüz M, Yaylı G. İkiyüzseksen bruselloz olgusunda farklı iki tedavinin karşılaştırılması. İnfeks Derg 2001; 15: 433-7. 